\title{
Erratum to: The effect of Katsura-uri (Japanese pickling melon, Cucumis melo var. conomon) and its derived ingredient methylthioacetic acid on energy metabolism during aerobic exercise
}

Wataru Aoi ${ }^{*}$, Kazuya Takeda², Azusa Sasaki², Yuki Hasegawa², Yasushi Nakamura², Eun Young Park², Kenji Sato ${ }^{3}$, Masayo Iwasa' ${ }^{1}$ Airi Nakayama', Mizuki Minamikawa ${ }^{4}$, Yukiko Kobayashi ${ }^{4}$, Koji Shirota ${ }^{5}$ and Noboru Suetome ${ }^{5}$

\section{Erratum to: SpringerPlus (2015) 4:377 DOI 10.1186/s40064-015-1144-y}

It has come to our attention that during production of the original article, an error was introduced into Table 1 during copyediting. The corrected Table 1 can be found below. The publisher apologises for inconvenience caused.

Table 1 Blood metabolic parameters in mice

\begin{tabular}{lcccc}
\hline & Sedentary & Exercise & & \\
\cline { 2 - 5 } & & Control & MTA-25 & MTA-250 \\
\hline Blood glucose $(\mathrm{mM})$ & $6.6 \pm 0.7$ & $7.8 \pm 1.4$ & $7.5 \pm 2.0$ & $6.7 \pm 1.0$ \\
Plasma NEFA $(\mu \mathrm{Eq} / \mathrm{L})$ & $880 \pm 281$ & $916 \pm 360$ & $883 \pm 529$ & $889 \pm 268$ \\
Blood ammonia $(\mu \mathrm{M})$ & $110 \pm 43$ & $135 \pm 37$ & $125 \pm 68$ & $107 \pm 33$ \\
Blood lactate $(\mathrm{mM})$ & - & $3.2 \pm 1.2$ & $2.5 \pm 0.7$ & $2.1 \pm 0.3^{\#}$ \\
\hline
\end{tabular}

Values are presented as mean \pm SD. Control, exercise group administered water; MTA-25, exercise group receiving 25 ppm MTA supplementation; MTA-250, exercise group receiving $250 \mathrm{ppm}$ MTA supplementation MTA methylthioacetic acid

\# $\mathrm{P}<0.05$ vs. control

\begin{abstract}
Author details
'Laboratory of Health Science, Graduate School of Life and Environmental Sciences, Kyoto Prefectural University, Kyoto 606-8522, Japan. ${ }^{2}$ Laboratory of Food Science, Graduate School of Life and Environmental Sciences, Kyoto Prefectural University, Kyoto 606-8522, Japan. ${ }^{3}$ Division of Applied Biosciences, Graduate School of Agriculture, Kyoto University, Kyoto 606-8502, Japan. ${ }^{4}$ Laboratory of Nutrition Science, Graduate School of Life and Environmental Sciences, Kyoto Prefectural University, Kyoto 606-8522, Japan. ${ }^{5}$ Horticultural Division, Kyoto Prefectural Agriculture, Forestry and Fisheries Technology Center, Kameoka 621-0806, Japan.
\end{abstract}

Published online: 21 September 2015

The online version of the original article can be found under doi:10.1186/s40064-015-1144-y.

*Correspondence: waoi@kpu.ac.jp

${ }^{1}$ Laboratory of Health Science, Graduate School of Life

and Environmental Sciences, Kyoto Prefectural University, Kyoto 606-8522,

Japan

Full list of author information is available at the end of the article

(c) 2015 Aoi et al. This article is distributed under the terms of the Creative Commons Attribution 4.0 International License (http:// creativecommons.org/licenses/by/4.0/, which permits unrestricted use, distribution, and reproduction in any medium,provided you give appropriate credit to the original author(s) and the source, provide a link to the Creative Commons license, andindicate if changes were made. 